\title{
ANALISA AKAR MASALAH RADIAL RUN OUT BAN MENGGUNAKAN DECISION TREE
}

\author{
Bambang Biantoro ${ }^{1}$, Hernadewita ${ }^{2}$ \\ ${ }^{1}$ Jurusan Teknik Industri, Universitas Mercubuana Jakarta \\ Email:b_biantoro@yahoo.com \\ ${ }^{2}$ Departemen Teknik Industri, Universitas Mercubuana Jakarta \\ Email: hernadewita@mercubuana.ac.id
}

Masuk: 01-10-2020, revisi: 06-10-2021, diterima untuk diterbitkan: 27-10-2021

\begin{abstract}
ABSTRAK
Pemecahan masalah pada proses produksi multistage merupakan tantangan untuk indusri. Pemanfaatan teknik modern seperti machine learning dalam pemecahan masalah kualitas terus dikembangkan. Salah satu machine learning adalah decision tree. Industri ban memasuki era industri revolusi 4.0 dengan adanya pemakaian teknologi informasi seperti barcode atau radio frequency identification. Pemanfaataan data dengan menggunakan machine learning dalam pencarian akar masalah bisa mendukung industri ban dalam kompetisi industri. Penelitian ini bertujuan untuk mengekplorasi data proses pada industri ban untuk memecahkan permasalahan kualitas ban yaitu radial run-out ban. Teknik pencarian akar masalah dilakukan menggunakan Clasification and Regression Tree (CART). Variabel input melibatkan 60 faktor dalam proses produksi. Dari penelitian didapatkan faktor yang mempengaruhi nilai radial run out adalah lot komponen Tread, Bead dan Sidewall. Untuk faktor penyebab tingginya radial run-out ban adalah variasi lot komponen Tread dan Bead. Model decision tree yang terbentuk memiliki tingkat presisi $74,7 \%$ dalam mendeteksi kejadian radial run-out berkategori tinggi. Efek perbaikan pada komponen lot Tread dan Bead yang dihasilkan dari decision tree dapat menurunkan tingkat defect radial run- out ban sebesar 99,9\%.
\end{abstract}

Kata Kunci: Decision tree; Analisa akar masalah; Radial run-out ban; Data mining

\begin{abstract}
Problem solving in the multistage production process is a challenge for the industry. The use of modern techniques such as machine learning in solving quality problems continues to be developed. One of the machine learning is decision tree. The tire industry entered the era of industrial revolution 4.0 with the use of information technology. Utilizing data using machine learning in finding the root cause of the problem can support the tire industry in industrial competition. This study aims to explore the process data in the tire industry to solve one of the tire quality problems, namely radial run-out tires. The technique of finding the root of the problem in this research is done using Classification and Regression Tree (CART) technique. Input variables involve 60 factors in the production process. From the research, it was found that the factors that influence the radial run out value are the lot of the Tread, Bead and Sidewall components. The factors causing the high radial run-out of the tires are the variations in the lot of the tire components Tread and Bead. The decision tree model that was formed has a precision level of $74.7 \%$ in detecting high radial run-out events. The effects of improvement on the lot tread and bead components resulting from the decision tree can reduce the defect of radial run out rate by $99.9 \%$.
\end{abstract}

Keywords: Decision tree; Root cause analysis; Radial run-out Tire; Data mining

\section{PENDAHULUAN}

Pemecahan permasalahan industri manufaktur sangat beragam dari pemecahan masalah yang paling sederhana plan-do-check-action (PDCA) sampai yang lebih komplek seperti six sigma. Seiring dengan berkembangnya teknologi informasi maka teknik pemecahan masalah terus berkembang dan dikombinasikan dengan teknik-teknik modern seperti machine-learning. 
Pemanfaatan data lampau dilakukan untuk mendapatkan pola-pola atau informasi yang ada di dalam kumpulan data atau dikenal sebagai data mining.

Proses produksi yang panjang/ multistage sangat membutuhkan teknik pemecahan masalah yang cepat. Kesulitan dalam pemecahan masalah pada proses multistage adalah kompleksitas proses melibatkan banyak variabel sehingga proses pencarian akar masalah lebih sulit. Variabel kemungkinan penyebab permasalahan sangat banyak dan bisa jadi juga merupakan kombinasi dari beberapa proses yang saling berinteraksi. Tanpa ada dukungan teknologi informasi maka pencarian akar masalah memakan waktu lama. Semakin lama proses pemecahan masalah dilakukan maka kerugian waktu proses ataupun jumlah produk tidak standar semakin besar.

Upaya peneliti menjawab tantangan dalam pemecahan permasalahan proses produksi multistage banyak dilakukan. Analisa model forward yaitu model dikembangkan dengan menganalisa kondisi proses sebelum dan memprediksi hasil pada proses berikutnya (Wuest, Irgens, \& Thoben, 2014), (P. Jiang, Jia, Wang, \& Zheng, 2014). Analisa model backward yaitu pencarian penyebab yang terjadi pada proses sebelumnya dengan melihat kondisi hasil yang ada seperti (Arif, Suryana, \& Hussin, 2013), (Kao, Hsieh, Chen, \& Lee, 2017). Model forward lebih banyak digunakan sebagai sistem kontrol atau montitoring proses sedangkan pada model backward lebih ditujukan dalam pencarian akar masalah yang menyebabkan produk tidak sesuai standar.

Industri ban adalah salah satu contoh proses produksi yang bersifat multistage. Dari bahan baku sampai menjadi produk jadi melibatkan beberapa tahapan proses antara lain pembentukan komponen ban, proses perakitan, proses pemasakan dan proses pemeriksaan produk akhir (Darayi, Eskandari, \& Geiger, 2013). Kualitas akhir dari produk ditentukan oleh kulitas material dan perlakuan dalam proses produksi. Analisa masalah terhadap produk akhir yang tidak masuk standar kualitas membutuhkan analisa yang rumit dikarenakan banyaknya variabel proses pada proses produksi yang panjang.

Pemanfaatan teknologi informasi seperti barcode ataupun radio frequency identification (Gao, Yang, \& Ning, 2010) sangat membantu dalam melakukan kemampuan telusur produk dengan sangat cepat. Pemakain teknologi mutakhir pada industri ban menjadi kebutuhan dalam menghadapi kompetisi industri yang tinggi dan menyongsong revolusi industri 4.0 (Biantoro, Trimarjoko, Purwanto, \& Rimawan, 2019). Transaksi proses produksi dapat dilakukan secara elektronik dan tingkat automasi yang tinggi. Data proses produksi tersedia secara elektronik memudahkan proses telusur dan merupakan peluang untuk pemanfatannya. Penelitian ini bertujuan untuk memanfaatkan data proses untuk meningkatkan kualitas produk mengunakan teknik data mining. Decision tree (DT) adalah salah satu teknik data mining untuk pencarian akar masalah membantu memperbaiki kualitas produk. Sebagaimana (Mueller, Greipel, Weber, \& Schmitt, 2018) melakukan simulasi automatisasi pencarian akar masalah menggunakan DT.

\section{LITERATUR REVIEW}

\section{Radial Run-Out Ban}

Ban merupakan produk composite yang terdiri dari beberapa komponen. Ban berfungsi sebagai penahan beban dan pengarah kendaraan. Harapan pelanggan terhadap kualitas ban adalah aspek kekuatan dan aspek fashion (Hadi et al., 2017). Kualitas ban dapat memberikan pengaruh pada kenyamanan berkendara. Salah satu kriteria kualitas ban yang berpengaruh terhadap 
kenyamanan adalah radial run-out ban(RRO) (Kenny, 1989). Mengingat pentingnya pengaruh RRO tehadap kenyamanan pengendara maka RRO menjadi obyek dalam penelitian ini.

RRO adalah ukuran kebulatan ban terhadap titik tengah perputaran ban. Illustrasi RRO pada Gambar 1. Pengukuran RRO dalam satuan millimeter. Pengukuran RRO dilakukan secara automatis pada mesin inspeksi pada proses final inspection atau tahap akhir produski. Hasil pengukuran RRO tercatat bersama dengan barcode identification yang dapat ditelusur ke proses produksi.

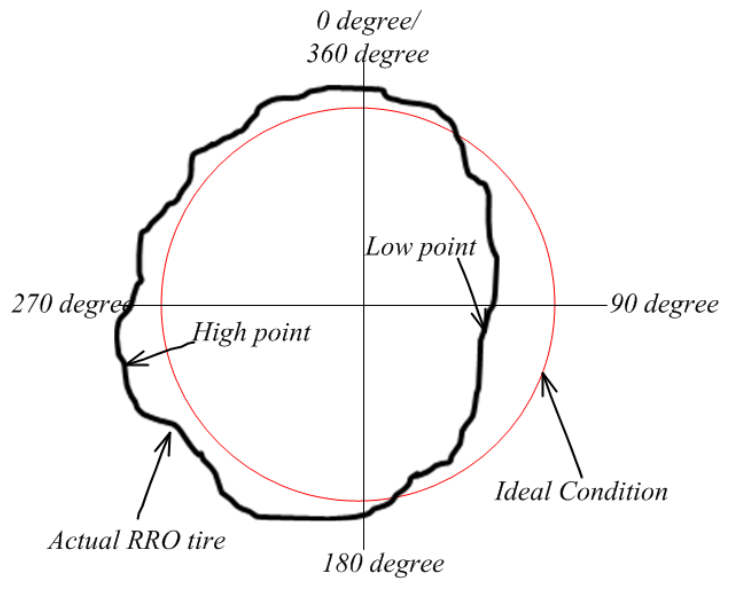

Gambar 1. Radial Run Out tire

\section{Decision Tree}

Decision tree (DT) merupakan salah satu teknik klasifikasi yang digunakan dalam sistem pendukung keputusan. Bagian dari model DT terdiri dari simpul/node dan cabang/branch. Setiap node menunjukkan feature penting dan setiap cabang menunjukkan keputusan (Chandrasekaran, Sonawane, Arulmozhi, \& Sriramya, 2020). DT dilakukan dengan menggunakan teknik atau urutan process sebagai berikut:

- Deskripsi statistik untuk melihat distribusi data dan uji normalitas data. Pada analisis DT distrubusi data normal menghasilkan DT yang lebih baik dibandingkan distribusi data tidak normal(Mueller et al., 2018).

- Konfirmasi faktor untuk menentukan faktor utama yang berkontribusi terhadap variabel output. Tahap ini dilakukan jika faktor input sangat kompleks untuk menghindari hasil DT yang rumit. Penelitian dengan melibatkan variabel input kurang dari 10 seperti (Mellisa, 2019), (Mueller et al., 2018) tidak melakukan pemilihan variabel, sedangkan penelitian dengan lebih dari 10 variable input (Song \& Lu, 2015) melakukan pemilihan variabel dominan. Penelitian dengan menggunakan pemilihan variabel dominan menunjukkan hasil akurasi dan presisi DT yang lebih baik (Arif et al., 2013) (Chokka \& Rani, 2019).

- Melakukan analisa DT untuk mengetahui faktor yang berpengaruh. Langkah langkah dalam analisa DT model adalah pembuatan diagram DT meliputi pemisahan/splitting dan pemberhentian/stoping criteria. DT yang terbentuk belum tentu menghasilkan kombinasi reule set yang optimal. Proses pemangkasan/ pruning terhadap cabang-cabang DT dapat dilakukan untuk meningkatkan performance DT (Seema, Rathi, \& Mamta, 2012) .

Algoritma teknik DT beragam, pada umumnya digunakan adalah CART (Classification and regression tree), C4.5, CHAID (Chi-square Automatic Interaction Detection), QUEST (Quick 
and Unbias, Efficient, Statistical Tree). Perbandingan pada masing masing metode terletak pada jenis data input dan variabel output serta pada proses pembentukan DT(Song \& Lu, 2015). Penelitian ini bertujuan untuk menemukan akar masalah yang mempengaruhi tingginya nilai RRO. Teknik DT pada penelitian ini digunakan metoda CART dimana variabel input dan output berbentuk kategori.

Evaluasi performance DT dapat dilakukan dengan melihat ketepatan model memprediksi sample. Pada penelitian bersifat mempredeksi ketepatan prediksi positif dan negative model maka indek accuracy umum digunakan untuk menilai performance model. Sedangkan untuk kasus penelitian yang hanya berfokus pada kebenaran model dalam memprediksi positive saja maka digunakan ukuran precision dan recall (C. Jiang, Liu, Ding, Liang, \& Duan, 2017).

Akurasi model DT berdasarkan simulasi(Mueller et al., 2018) dalam menentukan akar masalah ditentukan oleh faktor-faktor berikut ini :

- Bentuk distribusi normal menghasilkan DT yang lebih baik dibandingkan dengan distribusi data uniform

- Jumlah perbandingan antara produk Not OK dalam data minimal 7\%. DT tidak dapat mendeteksi akar masalah jika jumlah produk not OK kurang dari $7 \%$.

- Jumlah sample lebih banyak dapat meningkatkan akurasi dari model DT

- Semakin banyak kategori pada variabel maka model DT performancenya semakin menurun. Kondisi optimum pada simulasi adalah 15 kategori dalam variabel.

\section{METODE}

Berdasarkan literature review dan sifat objek yang diteliti maka penelitian ini dilakukan melalui tahapan sebagaimana pada Gambar 2. Tahapan penelitian meliputi:

- Analisa deskriptif untuk sifat data RRO dengan melakukan uji normalitas data RRO dan melakukan transformasi data yang diperlukan. Diskretisasi nilai RRO menjadi dua kategori yaitu high dan low kategori.

- Menghubungkan nilai RRO terhadap faktor faktor produksi yang dilalui meliputi informasi operator, mesin, material dan waktu pembuatan.

- Pencarian variabel utama untuk menyeleksi variabel kandidat yang ada sehingga dapat meningkatkan akurasi dari DT melalui analisa principal component analysis (PCA) dan partial least square (PLS).

- Melakukan analisa DT dengan metoda classification tree dengan variabel dependen adalah RRO yang telah di kategorikan dan faktor produksi yang menjadi variabel dominan sebagai variabel Independen

- Evaluasi model DT yang ada dan menentukan faktor- faktor penyebab tingginya nilai RRO

- Perbaikan terhadap faktor penyebab yang ditemukan pada model DT dan mengevaluasi pengaruh perbaikan pada tingkat defect produk. 


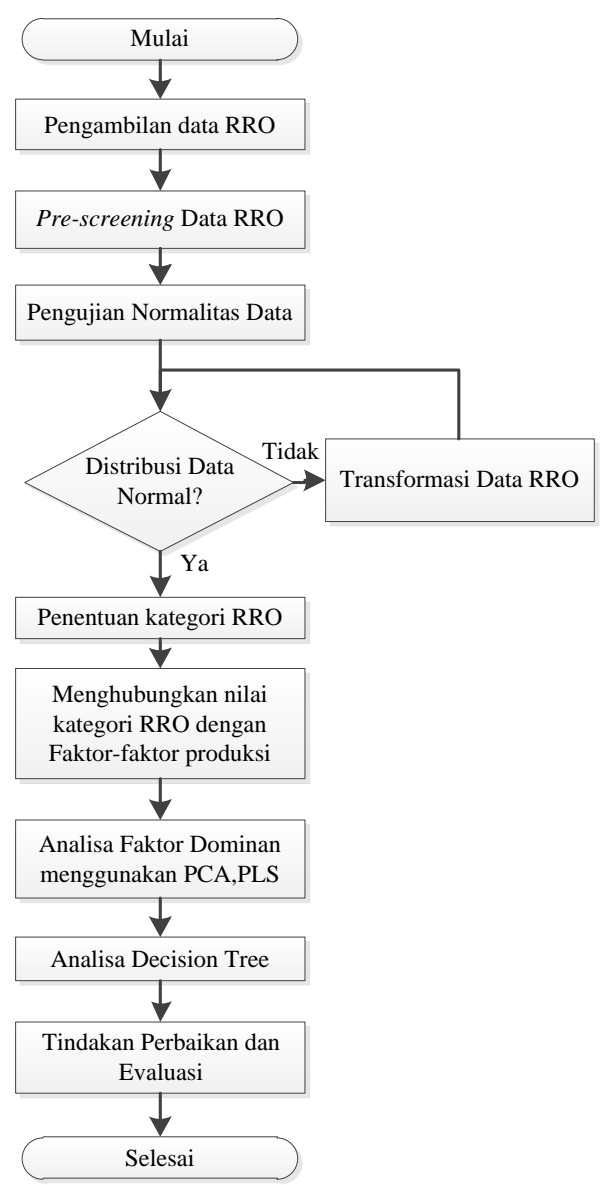

Gambar 2. Flow chart penelitian

\section{HASIL DAN PEMBAHASAN}

Data penelitian yang digunakan adalah data RRO ban selama proses inspeksi satu bulan pada produk ban truk dan bis yang digunakan pada posisi steer atau pengemudi. Jumlah total data 1480 pcs data. Deskripsi dari data RRO, dapat dilihat pada Gambar 3. Pada Gambar 3a terlihat distribusi data RRO condong ke arah negative dan hasil uji normalitas berdasarkan Kolmogorof Smirnoff (K-S d) p<0.05 menandakan bahwa data RRO tidak berdistribusi normal. Transformasi nilai data RRO dilakukan menggunakan persamaan 1 menjadi RROt. Gambar 3b menunjukkan histogram data RROt yang sudah ditransformasi. Nilai K-S d untuk p adalah 0.20 yang menunjukkan distribusi data sudah normal.

$\mathrm{RROt}=\log (\mathrm{RRO})$ 


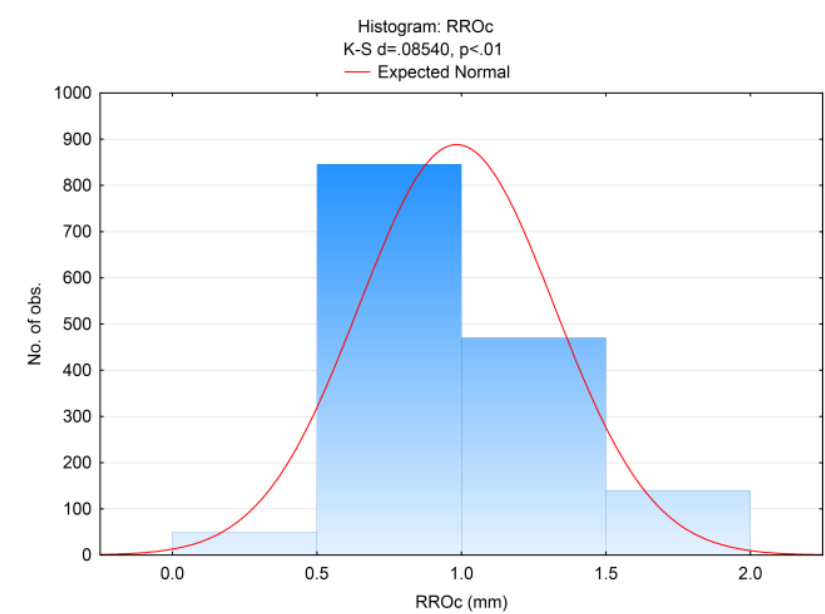

a. Sebelum transformasi

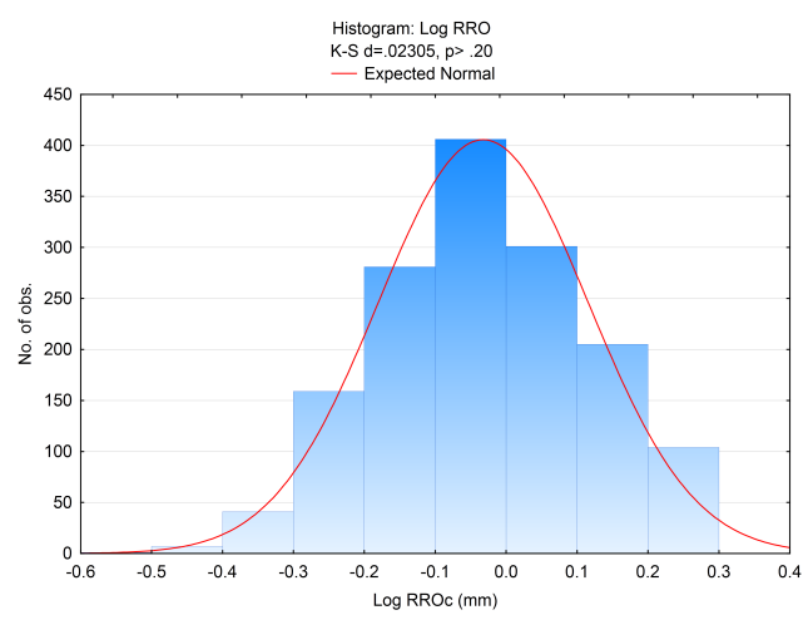

b. Sesudah Transformasi

Gambar 3. Histogram data RRO

Pembagian variabel output menjadi kategori bergantung pada sifat produk. Penelitian (Mueller et al., 2018) dengan sifat produk pada nilai target tertentu membagi kelas menjadi dua dengan ketentuan nilai sesuai toleransi menjadi kelas $O K$ dan nilai diluar toleransi menjadi not-OK. Variabel output penelitian ini bersifat nilai tagetnya adalah seminimum mungkin. Pembagian kelas RRO menjadi dua dengan ketentuan nilai RROt lebih besar atau sama dengan 0 dikategorikan sebagai high RRO dan RROt $<0$ dikategorikan sebagai low RRO. Dengan cara demikian maka jumlah high RRO dalam data adalah sebesar $41.3 \%$. Jumlah high RRO ini memenuhi kriteria minimum untuk digunakan dalam analisa akar masalah dengan model DT.

Pada setiap data ban terdapat no unik atau barcode identification yang dapat digunakan sebagai traceback terhadap proses produksi sehingga didapatkan data faktor-faktor proses produksi. Data penelitian melibatkan data sejumlah 60 attribute. Sebanyak 4\% data tidak lengkap dan di hilangkan pada proses selanjutnya. Penyederhanan variabel input dilakukan menggunakan feature selection pada software SAS yang berprinsip pada principal component analysis (PCA) dan partial least square (PLS). Gambar 4 menunjukkan 10 variabel input dominan yang mempengaruhi klasifikasi RROt.

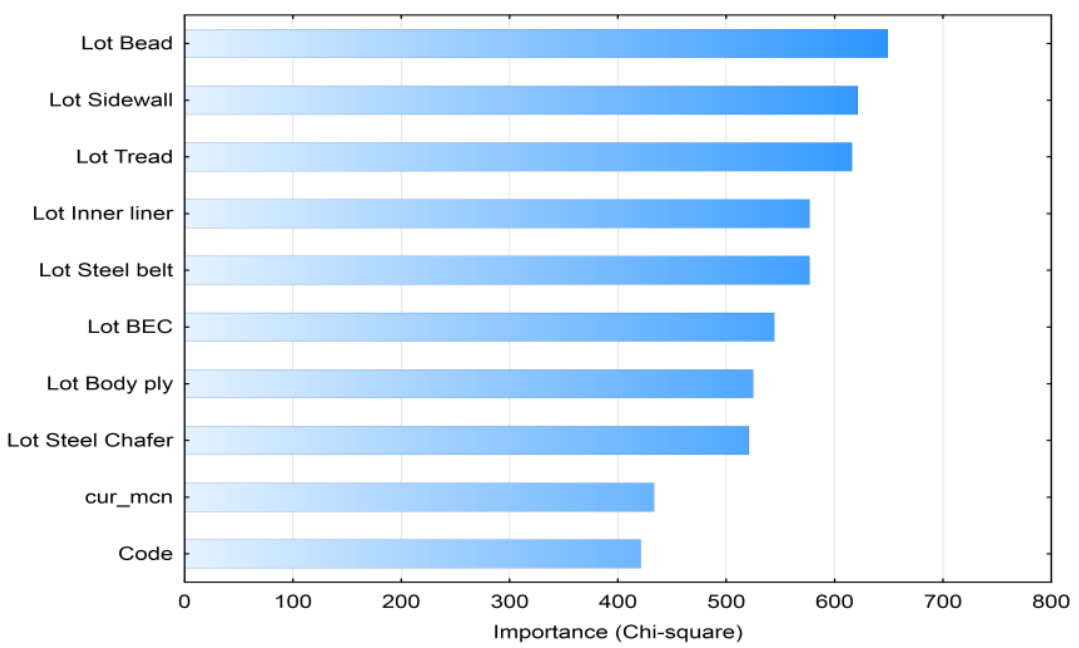

Gambar 4. 10 Variabel Dominan terhadap RROt 
Tabel 1. Variabel untuk analisa DT

\begin{tabular}{ccccc}
\hline No & Attribut & Deskripsi & Jenis Variabel & Jenis data \\
\hline 1 & RROt & $\begin{array}{c}\text { Nilai Kualitas ban dalam satuan millimeter } \\
\text { yang sudah ditransformasi }\end{array}$ & Dependent & kategori \\
\hline 2 & Lot Bead & Lot material Bead & Independent & kategori \\
\hline 3 & Lot Sidewall & Lot material Sidewall & Independent & kategori \\
\hline 4 & Lot Tread & Lot material Tread & Independent & kategori \\
\hline 5 & Lot Inner liner & Lot material Inner Liner & Independent & kategori \\
\hline 6 & Lot BEC & Lot material Belt Edge Cushion & Independent & kategori \\
\hline 7 & Lot Body Ply & Lot material Body Ply & Independent & kategori \\
\hline 8 & Lot Steel & Lot material Steel Chafer & Independent & kategori \\
\hline 9 & Curing_mcn & Nomer posisi mesin cuing & Independent & kategori \\
\hline 10 & Code & Jenis produk ban & Independent & kategori \\
\hline
\end{tabular}

DT analisis menggunakan software SAS dengan metoda interactive decision tree CART. DT dikembangkan berdasarkan kondisi pemisahan indek menggunakan gini indeks dan kriteria pemberhentian adalah jumlah node minimal 125 data. Penentuan kriteria perberhentian ini dilakukan dengan mempertimbangkan tingkat kompleksitas DT yang akan dihasilkan dan tujuan dari DT untuk mencari faktor dominan akar masalah high RRO (Song \& Lu, 2015). Semakin tinggi tingkat kompleksitas akan semakin sulit dalam menentukan faktor dan semakin rumit dalam dilakukan perbaikan.

Gambar 4 menunjukkan bahwa DT yang terbentuk memiliki jumlah non terminal node sebanyak 5 dan terminal node sebanyak 6. Dari 10 variabel yang terlibat hanya 3 variabel yang muncul. Hal ini menandakan bahwa 3 variabel ini dominan mempengaruhi nilai RRO. Pada model DT terlihat bahwa RROt dengan kategori high pada ada node ID no 2,4,5,6 dan 7 dengan melibatkan komponen lot tread dan lot bead. DT dapat menunjukkan komponen dan lot secara spesifik.

Evaluasi model DT dapat dilakukan dengan melihat confusion matrik sebagaimana pada Tabel 2. Pada penelitian ini fokus utama adalah mencari akar masalah dari tingginya nilai RRO oleh karenanya precision dan recall menjadi tolok ukur dalam menilai performance model DT. Tabel 2 menunjukkan bahwa DT dapat memprediksi kejadian high RRO sebesar 74.7\% dan kebenaran hasil prediksi model DT pada high RRO adalah 76.4\%. Evaluasi ini berbeda dengan penelitian yang bertujuan untuk menggunakan DT sebagai prediksi pada semua kondisi atau secara total yang umumnya menggunakan tingkat akurasi model. 
Num. of non-terminal nodes: 5 , Num. of terminal nodes: 6

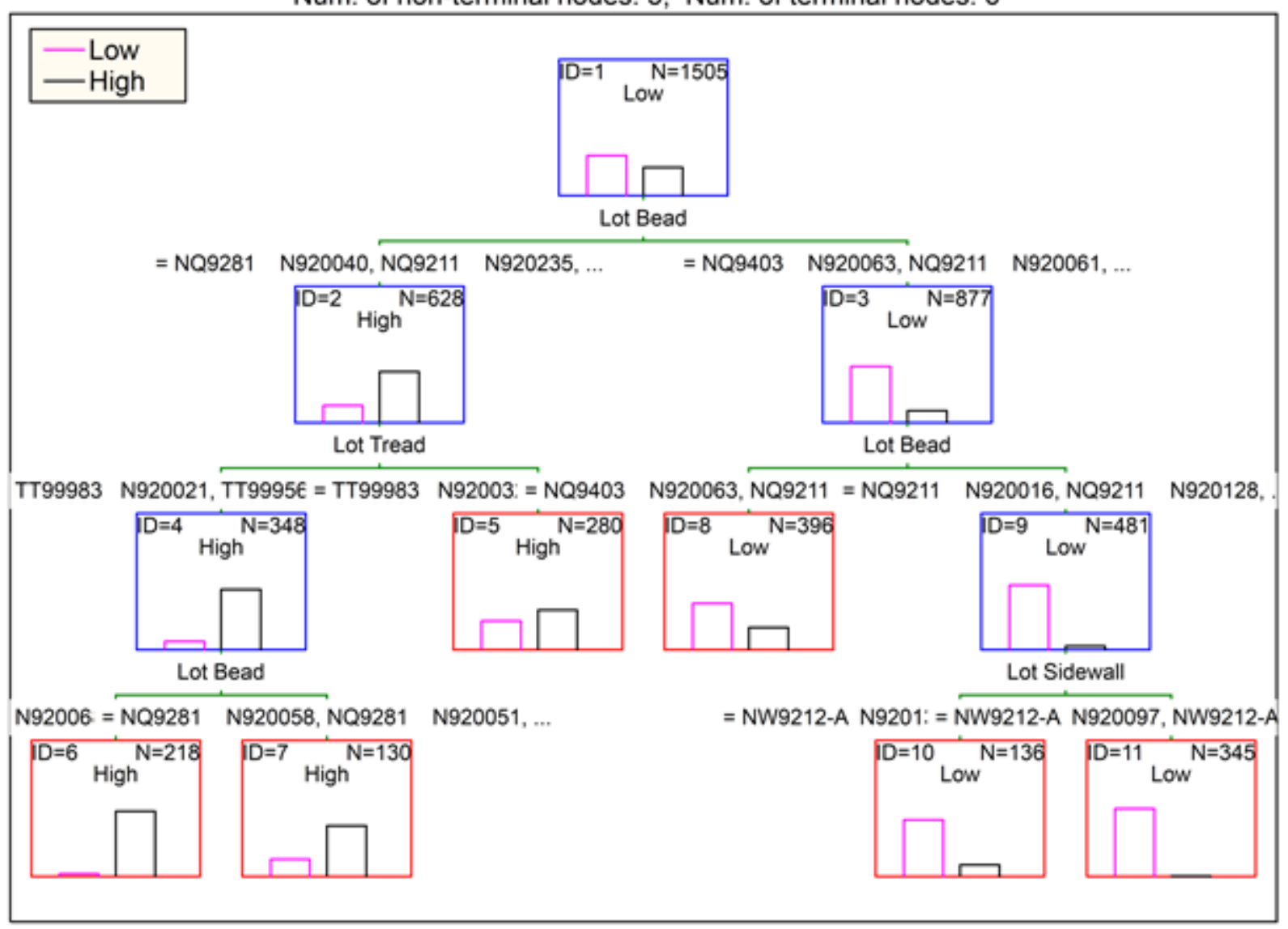

Gambar 5. Decision Tree analysis RROt

Tabel 2. Confusion matrix

\begin{tabular}{|c|c|c|c|}
\hline \multirow{4}{*}{ Actual RROt } & \multirow{4}{*}{$\begin{array}{l}\text { Low } \\
\text { High }\end{array}$} & \multicolumn{2}{|c|}{ Prediksi RROt } \\
\hline & & \multirow{2}{*}{${ }^{\text {Low }}$} & High \\
\hline & & & 158 \\
\hline & & 144 & 467 \\
\hline Precision & & $74,7 \%$ & \\
\hline Recall & & $76,4 \%$ & \\
\hline
\end{tabular}

Perbaikan pada proses dengan fokus pada hasil analisa DT yaitu perbaikkan pada komponen Tread dan Bead khususnya pada lot dengan kategori high RRO. Item perbaikkan yang dilakukan adalah mengurangi variasi panjang komponen tread dan bead serta metode penyambungan komponen tersebut. Evaluasi terhadap hasil perbaikan kedua komponen dilakukan dengan melihat tingkat defect RRO ban. Perbandingan defect RRO ban menunjukkan penurunan defect RRO dari $8.69 \%$ menjadi $0.19 \%$ atau berkurang sebesar $99.9 \%$.

\section{KESIMPULAN}

Berdasarkan analisa DT maka dapat disimpulkan bahwa:

- Kategorisasi output menjadi OK- not OK atau bad-good tergantung pada sifat produk atau variabel yang dianalisa. 
- Pada proses penentuan stopping kriteria harus diseimbangkan antara kompleksitas model DT dengan tujuan DT. Analisa DT yang bertujuan untuk pencarian faktor dominan masalah dapat menggunakan DT lebih sederhana.

- Tidak semua faktor dominan yang terlibat dalam DT akan muncul. Faktor akan muncul dalam DT ketika stoping criteria telah terpenuhi. Faktor dominan yang muncul dalam DT adalah lot komponen Tread, Bead dan Sidewall. Faktor penyebab permasalahan high RRO ban pada penelitian ini adalah lot komponen Tread dan Bead.

- Perbaikan terhadap akar masalah yang diidentifikasi melalui DT menghasilkan penurunan defect RRO secara signifikan.

Penelitian penggunaan DT dalam mencari akar masalah untuk permasalahan kualitas masih perlu dikembangkan. Penentuan stopping criteria optimal perlu di uji agar tingkat kompleksitas dan tingkat precision model berjalan seimbang.

\section{Ucapan Terima Kasih}

Penelitian ini didukung oleh Kementerian Pendidikan / Kepala Badan Riset dan Inovasi Nasional Republik Indonesia melalui Program Magister Hibah Penelitian Tesis (PTM) Tahun 2020 dan Lembaga Penelitian dan Pengabdian kepada Masyarakat Universitas Mercubuana.

\section{REFERENSI}

Arif, F., Suryana, N., \& Hussin, B. (2013). A data mining approach for developing quality prediction model in multi-stage manufacturing. International Journal of Computer Applications, 69(22), 35-40.

Biantoro, B., Trimarjoko, A., Purwanto, C., \& Rimawan, E. (2019). Case Study: Acceptance Analysis for New Tire Building Machine Technology using Overall Equipment Effectiveness Methodology. International Journal of Innovative Science and Research Technology, 4(1).

Chandrasekaran, M., Sonawane, P. R., Arulmozhi, P., \& Sriramya, P. (2020). Prediction of Gear Pitting Defect by Using Decision Tree Classifier Machine Learning Algorithm. Journal of Critical Reviews, 7(9), 159-162.

Chokka, A., \& Rani, K. S. (2019). PCA based regression decision tree classification for somatic mutations. International Journal of Engineering and Advanced Technology, 8(6 Special Issue 3), 1095-1102. https://doi.org/10.35940/ijeat.F1181.0986S319

Darayi, M., Eskandari, H., \& Geiger, C. D. (2013). Using Simulation-Based Optimization to Improve Performance At a Tire Manufacturing Company. QScience Connect, 13.

Gao, Y., Yang, D., \& Ning, W. (2010). Research on Manufacturing Process Traceability in Tire Enterprise. Applied Mechanic and Material, 47(December), 485-488. https://doi.org/10.4028/www.scientific.net/AMM.44-47.485

Hadi, H. A., Purba, H. H., Indarto, K. S., Gomgom, R., Simarmata, P., \& Putra, G. P. (2017). The implementation of quality function deployment (QFD) in tire industry. ComTech, 8(4), 223-228.

Jiang, C., Liu, Y., Ding, Y., Liang, K., \& Duan, R. (2017). Capturing helpful reviews from social media for product quality improvement: a multi-class classification approach. International Journal of Production Research, 7543(March), 0. https://doi.org/10.1080/00207543.2017.1304664

Jiang, P., Jia, F., Wang, Y., \& Zheng, M. (2014). Real-time quality monitoring and predicting model based on error propagation networks for multistage machining processes. Journal of Intelligent Manufacturing, 25(3), 521-538. https://doi.org/10.1007/s10845-012-0703-0 
Kenny, T. M. (1989). Quantifying Tire, Rim and Vehicle Effect on Ride Quality. In International Congress and Exposition (pp. 1-9). Detroit, Michigan, USA: SAE.

Mellisa, I. (2019). Building Data Mining Decision Tree Model for Predicting Employee Performance. Journal of Applied Information Communication and Technology, 6(2), 7586. https://doi.org/10.33555/ejaict.v6i2.79

Mueller, T., Greipel, J., Weber, T., \& Schmitt, R. H. (2018). Automated Root Cause Analysis of Non-conformities with Machine Learning Algorithms. Journal of Machine Engineering, 18(4), 60-72.

Seema, Rathi, M., \& Mamta. (2012). Decision Tree: Data Mining Techniques. International Journal of Latest Trends in Engineering and Technology (IJLTET), 1(3), 150-155.

Song, Y., \& Lu, Y. (2015). Decision tree methods : applications for classification and prediction. Shanghai Arch Psychiatry, 27(2), 130-135.

Wuest, T., Irgens, C., \& Thoben, K. D. (2014). An approach to monitoring quality in manufacturing using supervised machine learning on product state data. Journal of Intelligent Manufacturing, 25(5), 1167-1180. 